\title{
INTRODUCTION \\ ERNEST SOSA: A PHILOSOPHY FOR THE 21sT CENTURY
}

Waldomiro José Silva Filho ${ }^{1}$

The main, fundamental questions that most interest me are those that interested Plato in his Theatetus and Descartes in his Meditations, and some of interest to Aristotle in his Nicomachean Ethics. [...] The span of opinions presented by the issues taken up in those great works are among those we still debate today. I expect that they are ones we'll still debate tomorrow.

Ernest Sosa

Praise is appropriate to virtue; for from virtue men perform noble actions.

Aristotle, Micomachean ethics, 1102a

1. In the early spring of 2016, on an especially nice day, Ernest Sosa welcomed me into his New York City apartment. I had brought him a copy of the book The Complete Stories by the Brazilian writer Clarice Lispector, published in the year before. We talked about the topics that have motivated my great interest in his work, especially his interpretation of ancient skepticism and his thesis on the notion of agency.

At that time I was working on organizing a book on the problem of epistemic reflection from Sosa's conception of reflective knowledge - this project materialized three years later with the publication of Thinking about

${ }^{1}$ Full Professor at the Philosophy Department of Federal University of Bahia (UFBA), Salvador, BA - Brazil. Researcher of the CNPq, Brazil. (D) https://orcid.org/0000-0002-0874-9599 E-mail: waldojsf@ufba.br

https://doi.org/10.1590/0101-3173.2021.v44dossier2.02.p13 
Oneself: The place and value of reflection in Philosophy and Psychology (SILVA FILHO \& TATEO 2019). We went to lunch in a wonderful Asian restaurant and the conversation continued both fraternal and animated: Ernie showed interest in my (hesitant and obscure) opinions and there was also in him a sincere curiosity about what was happening in the Brazilian philosophical community. I had met Prof. Ernest Sosa other times in events and conferences, but this was the first time we talked. Everything surrounding that meeting acquired its real dimension only minutes after we had parted and I walked through the restless streets of New York with a hurricane devastating the stillness of my soul. I wondered what Sosa's day-to-day academic relationships with colleagues and students might be like - I kept thinking that there was a strong link between the deeper motivations of his work and the way he leads his own life.

I hope that it will not seem strange that I begin this text by narrating a prosaic encounter and that I am here pointing out the moral qualities of a person who is celebrated for his work. One of the side effects of the professionalization of philosophy within prestigious university institutions is that we come to expect from philosophers only good arguments and demonstrations, but we don't expect these arguments to be in the service of the search for the good life or the search for a better way of conducting one's own life. We have become used to thinking of philosophy as a discipline that has its territory confined to the space of seminars and congresses; we are no longer used to living according to a wisdom that is born out of philosophy.

Besides considering his original contribution to philosophical disciplines with his papers and books, there are three characteristics in Ernie's human and philosophical attitude that make him a unique character in the philosophical world. (a) Ernie is a man of a wide and rich intellectual culture, something that has enabled him at the same time to think about the great challenges of contemporary philosophy and also to be a critical interpreter of classical philosophers such as Plato, Aristotle, Sextus Empiricus, and Descartes; (b) Ernie has the exceptional ability to animate an extended dialogue with philosophers of various cultural expressions, from the European tradition to Asia (as for example, his interlocution with Chinese thought) and; (c) Ernie is a generous man, willing to dispute ideas and opinions with renowned intellectuals and young undergraduate students. 
2. The works of Ernest Sosa claims to provide original and thoughtprovoking contributions to contemporary epistemology in setting a new direction for old dilemmas about the nature and value of knowledge. As we know, virtue epistemology (SOSA, 1991; 2007; 2009) proposes a solution to the disputes that monopolized the epistemological debates of the $1960 \mathrm{~s}$ and 1980s, between, on the one hand, foundational and coherentist theories about epistemic justification and, on the other hand, externalist and internalist conceptions about the nature of knowledge. These foundational and coherentist, externalist and internalist positions address aspects relevant to our cognitive lives. However, their defenders are inclined to refute other positions, even when they contain intuitively relevant ideas: can we set aside the idea that we are natural beings and that the way in which we are embedded in the natural world plays a constitutive role in our cognitive achievements? Could we reject the idea that reflection and a broad understanding of our cognitive achievements play a central role in our lives?

Sosa argues that knowledge requires true belief produced by innate or acquired skills and competences that allow someone to pursue and reach the truth or another epistemic goal. The concept of apt performance is crucial for both knowledge and action because it involves the idea of an achievement based on the deliberate endeavor of the person in her capacity as an agent. In this sense, Sosa $(2007$, p. $22-43)$ uses the example of an archer shooting an arrow at a target in order to illustrate the fact that one of the demands which may be required for knowledge is the fact that the cognitive agent must undertake a specific type of performance based on her skills. Once this archer is truly competent, we expect that she will hit the target because of her skill, not because of some other factor. The cognitive agent is someone who achieves an epistemic goal in virtue of her through her performance.

However, considering the human condition, aptitude and ability to reach the truth is not enough. Sosa talks about a special performance that addresses strictly human challenges, a performance that additionally requires the trajectory of intentional and conscious inquiry, the evaluation of one's own intellectual tools and capabilities, and the cooperation of other people. For him, the fully apt performance "goes beyond the merely successful, the competent, and even the reflectively apt" (SOSA, 2015, p. 87); this goes, from Plato and Sextus to Chisholm, to the core of our human condition. 
3. It is very important to point out that Sosa suggests that the highest level of human knowledge, full knowledge, has value because it contributes to human flourishing-by which human flourishing is understood in an Aristotelian sense as human activity in accordance with the best and most complete virtue and explains why knowledge is important for human life. ${ }^{2}$ This topic has been treated especially in Knowing Full Well (SOSA, 2011), Judgment, and Agency (SOSA, 2015) and, more recently, has received new developments in his proposal for a Telic Epistemology of Virtue in Epistemic Explanations (SOSA, 2021).

For a telic virtue epistemology, the proper domain of the epistemic is one in which we act in pursuit of truth or a higher epistemic good and are meant to do so appropriately, using our best intellectual resources, such as intentional and conscious judgment, insight, the belief culture of the human community, and the cooperation of others also engaged in the pursuit of the epistemic good. Moreover, this path of epistemology is concerned with "humanistic questions" and lessons in epistemology appropriate to the liberal arts, including the humanities and philosophy itself.

In this regard, what is necessary for human flourishing is the engagement in this domain. However, wouldn't human flourishing be just another rationalist delusion? Do we really need a form of knowledge as Ernest Sosa suggests?

We don't need to consult a treatise on philosophy to be aware of the precarious, insecure and fallible situation in which human beings find themselves. Besides the challenges and pitfalls of nature, our epistemic vices and irresponsibilities are a permanent risk. Therefore, Sosa wonders:

Why is knowledge better than merely subjectively competent belief? Why is knowledge better than merely true belief? Well, compare this: Why is wellbased happiness or pleasure better than the equally subjectively pleasant tone of the subject in an experience machine victimized by a controlling demon? The life of such a hedonic victim is no more a flourishing human life than is the illusory life of a Matrix dweller, which indeed can itself include much illusory or false pleasure. The subjective character would be real enough, of course, but its content would be illusory nonetheless. Victims of experience machines and Matrix frameworks would have subjective enjoyment, true enough, but their lives would fall horribly short

${ }^{2}$ For Berit Brogaard (2014, 15), “[i]ntellectual flourishing is the epistemic equivalent of Aristotle's eudaimonia (well-being, flourishing, happiness). For Aristotle, eudaimonia requires having a virtuous character, being loved, and having close friends. If we extend this idea to intellectual flourishing, then intellectual flourishing might involve such things as being intellectually virtuous, being respected intellectually, and having good intellectual cohorts." 
nonetheless, as is revealed by our wholehearted preferences when a choice is forced. Better truth than falsity in a human life, better competence than incompetence, yes, but better yet, what is required for the full human flourishing of that life, which is incompatible with a life of illusion, in the various forms canvassed. (SOSA, 2015, p. 189-90).

Perhaps this is a problem that the human species has always needed to face, since time immemorial. It is impossible to ignore that today, in this insane century in which we have the difficult task of choosing between life and democracy or destruction and extinction, the shadows of illusion and deception are fatal... and we need more than truth and skills.

4. Ernie is a philosopher in the ancient sense of this word: gentle, polite, wise, and attentive to the word of his interlocutor, creator of a new horizon for thought. The size of his work has the same greatness as his humanity. And perhaps this helps to understand one of the characteristics of his contribution to philosophy for this bizarre and cruel century, a century that challenges our very sense of humanity: by taking up the theme of intellectual virtues and shifting the epistemological problem from the nature of belief to the performances of agents, Sosa offers us a philosophy focused on our ability to judge our cognitive powers and act in light of that judgment. Indeed, the challenges of life in this 21 st century is much more than having knowledge and having technology; we need to be able to evaluate the purposes for our actions and expect the best from ourselves.

Ernie offers us a philosophy of virtues and this, of course, concerns the way we live. It is not possible to ignore that we need to cultivate our best powers and virtues to reach knowledge; we need also, with these powers, to create a civil and extended friendship; we need, with these powers, to combat the vices and illusions that, for the first time in history, on a planetary scale, threaten the very existence of life. ${ }^{3}$

Happy birthday, Ernie, and thank you very much.

\footnotetext{
${ }^{3}$ I thank my dear friend Giovanni Rolla for his reading and suggestions. I also thank the National Council for Scientific Research (CNPq) of Brazil; this work is part of the project "Reflection, Dialogue and Epistemic Virtues: An Interpersonal Perspective on Reflection”, process n. 311816/2019-3.
} 


\section{REFERENCES}

ARISTOTLE. The Nicomachean Ethics. Translated by David Ross, revised with an introduction and note by Lesley Brown. Oxford: Oxford University Press. 2001.

BROGAARD, Berit. Intellectual Flourishing as the Fundamental Epistemic Norm. In: LITTLEJOHN, C. \& TURRI, J. (Eds.) Epistemic Norms: New essays on action, belief, and assertion. Oxford: Oxford University Press, p. 11- 31, 2014.

SOSA, Ernest. Knowledge in Perspective: Selected Essays in Epistemology. Cambridge: Cambridge University Press, 1991.

SOSA, Ernest. A Virtue Epistemology: Apt Belief and Reflective Knowledge, Vol. I. Oxford: Oxford University Press, 2007.

SOSA, Ernest. Reflective Knowledge: Apt Belief and Reflective Knowledge, Vol. II. Oxford: Oxford University Press, 2009.

SOSA, Ernest. Knowing Full Well. Princeton, Oxford: Princeton University Press, 2011.

SOSA, Ernest. Judgment and Agency. Oxford: Oxford University Press, 2015.

SOSA, Ernest. Epistemic Explanations: A Theory of Telic Normativity, and What It Explains. Oxford: Oxford University Press, 2021.

SILVA FILHO, Waldomiro J. \& TATEO, Luca (Eds.). Thinking about Oneself: The place and value of reflection in Philosophy and Psychology. Cham: Springer, 2019.

Received: $10 / 4 / 2021$

Approved: 22/4/2021 